\title{
Body shape index versus body mass index as correlates of health risk in young healthy sedentary men
}

\author{
Marzena Malara, Anna Kęska, Joanna Tkaczyk and Grażyna Lutosławska*
}

\begin{abstract}
Recently a new simply calculated index of body composition -a body shape index (ABSI) has been introduced as an index more reliable than BMI of association between body composition and all-cause mortality. However, until now associations between ABSI and metabolic risk factors have not been evaluated. A total of 114 male university students not engaged in any planned physical activity participated in the present study. Anthropometric measurements (weight, height, waist circumference) were recorded. Body mass index (BMI) was calculated from weight and height, body shape index (ABSI) was calculated from waist circumference, weight, height and BMI. Blood was withdrawn after an overnight fast from the antecubital vein. Triacylglycerols, total cholesterol and HDL-cholesterol levels in plasma were determined using colorimetric methods and Randox commercial kits. Plasma LDL-cholesterol concentrations were calculated according to the Friedewald formula. Circulating insulin was assayed using a standard radioimmunological method with monoclonal antibodies against insulin and BioSource commercial kits. BMI was slightly, but significantly correlated only with circulating TG $(r=0.330, p<0.001)$ In contrast, $A B S I$ was slightly, but significantly correlated with plasma levels of insulin ( $r=0.360, p<0.001)$, TC ( $r=0.270, p<0.002)$, LDL-C and non-HDL-C ( $r=0.300, p<0.001)$. In participants at the upper quartile of BMI circulating TG was higher (by $50 \%, \mathrm{p}<0.05$ ) than in their counterparts at the lower BMl quartile. Subjects representing the upper quartile of $A B S I$ were characterized by higher plasma levels of insulin, TC, LDL-C and non-HDL in comparison with subjects at the lower ABSI quartile. (by $92 \%, 11 . \%, 29 \%$ and $21 \%$ respectively, p<0.001). ABSI, a new simply calculated index of body fat seems to more accurately depict the variability in circulating insulin and lipoproteins than BMI at least in young, healthy male subjects.
\end{abstract}

Keywords: Body mass index, Body shape index, Insulin, Lipoproteins

\section{Background}

At present obesity is recognized as the main cause of type 2 diabetes, cardiovascular disease and an important contributing factor in some cancers [1]. In consequence, precise obesity criteria and diagnosis are of special importance in medical practice.

There is a wide range of methods for body fat determination, which are suitable in laboratory practice (BIA, DEXA, CT, and MRI); however, they require costly equipment, which is not always available [2-4]. Much simpler skinfold measurement are time-consuming and have to be performed by experienced technicians [5]. Thus, they are not suitable either for everyday medical practice or in

\footnotetext{
* Correspondence: grazyna.lutoslawska@awf.edu.pl

Department of Biochemistry and Biology, Józef Pilsudski University of Physical Education, Box 55, 00-968 Warsaw, Poland
}

population-based studies. According to WHO recommendations, the body mass index (BMI) calculated from body weight and height and waist circumference (WC) are a valid indicators of fatness and this assumption has been supported by many studies concerning their associations with health risk [6-8]. On the other hand, there are data questioning BMI reliability and indicating that it provides a false diagnosis of body fatness $[9,10]$. There are also data indicating that regional fat distribution, but not total body fat stores, are related to metabolic disturbances and health risks $[11,12]$. Furthermore, it has been demonstrated that WHO standards of BMI are not suitable for the evaluation of body fat with respect to ethnicity [13].

Similarly, many doubts exist with respect to associations between BMI and mortality. Assuming that BMI provides reliable information concerning body fatness and taking 
into account detrimental effects of fat excess on health and mortality, it is not clear why the BMI-mortality relationship is U-shaped, suggesting high mortality in both lean and obese humans [14-16]. Moreover, it is worth noting that in young healthy adults BMI, but also other surrogate indices of fatness (e.g. waist-to-height ratio, body adiposity index) provide poor prognosis of fat mass since they reflect mostly skeletal muscle mass $[17,18]$.

In the literature there are many other simple surrogate indices of body fat such as the waist-to-height ratio (e.g. weight-to-height ratio-WtHR), conicity index - CI, body adiposity index -BAI), however, their validity in respect to BMI is still under debate [19-22]. Recently Krakauer and Krakauer [23] proposed a new simply calculated index of body composition (a body shape index - ABSI) as more reliable than BMI in determination of association between all-cause mortality and body composition. However, data concerning relationship of ABSI with health risk are controversial. ABSI was found to predict resting blood pressure in adolescents more precisely than BMI [24]. On the contrary, ABSI predictive ability was not better than BMI with respect to type 2 diabetes, hypertension and cardiovascular disease in Chinese and Iranian populations [25-27]. The reason for this discrepancy is unknown, however, it may be due to ethnic differences in body fat distribution [28]. In addition, it cannot be excluded that BMI reflecting mostly total body fat differs in its relationship to metabolic variables from ABSI, which encompasses waist circumference, thus at least partially depicts fat distribution [29].

Thus, this study was undertaken and aimed at the evaluation of the relationship between ABSI and BMI and biochemical variables contributing to health risk in sedentary young male adults.

\section{Methods \\ Participants}

We studied a sample of 114 male university students recruited through word-of-mouth, and posters displayed at the university and in student dormitories. They were selected from 148 volunteers because they agreed to venous blood withdrawal under fasting conditions. All participants were healthy non-smokers not engaged in planned physical activity and not taking any medication on a regular basis. They were informed about procedures and all provided their written consent. The study protocol was accepted by the local ethics committee at the Jósef Piłsudski University of Physical Education.

\section{Anthropometric measurements}

Body mass was measured to the nearest $0.1 \mathrm{~kg}$ and body height to the nearest $0.5 \mathrm{~cm}$ using standard medical equipment in subjects wearing light indoor clothing without shoes, jackets and sweaters. Body mass index
(BMI) was calculated as body mass (kg) divided by height $(\mathrm{m})$ squared. The subjects' adiposity was classified according to WHO standards: underweight was defined as $\mathrm{BMI}<18.5$, normal weight as $\mathrm{BMI} \geq 18.5$ and $<25$, overweight as $\mathrm{BMI} \geq 25$ to $\mathrm{BMI}<30$, and obesity as a BMI $\geq 30$ [30]. Waist circumference (WC) was measured in the midway section between the lower edge of the ribs and the iliac crest with an accuracy of $0.1 \mathrm{~cm}$ using nonstretchable tape and values $<102 \mathrm{~cm}$ were accepted as normal [30]. All measurements were performed twice but in case of divergent results were repeated for the third time. A Body Shape Index (ABSI) was calculated according to Krakauer and Krakauer [23] and the following formula:

$$
\text { ABSI }=\mathrm{WC}(\mathrm{m}) /\left[\mathrm{BMI}^{2 / 3} \times \text { height }(\mathrm{m})^{1 / 2}\right]
$$

\section{Blood tests}

Participants were asked to refrain from physical activity for $48 \mathrm{~h}$ before blood sampling. They were tested in the morning (8:00-8:30 a.m.) after an overnight fast. Venous blood was collected under aseptic conditions into plastic tubes containing anticoagulant and centrifuged at $4^{\circ} \mathrm{C}$. Plasma was stored at $-70^{\circ}$ until analysis.

Glucose was determined using the GOD-PAP method. Circulating glucose was classified according to the International Diabetes Federation with $5.5 \mathrm{mmol} / \mathrm{l}$ accepted as the upper level [31]. Triacylglycerols (TG), total cholesterol (TC), and HDL-cholesterol (HDL-C) were assayed colorimetrically. All variables were determined using commercial kits (Randox Laboratories, Great Britain). Coefficients of variation for these analyses did not exceed $5 \%$. The plasma level of LDL-cholesterol (LDL-C) was calculated according to the Friedewald equation [32]. Non-HDL-cholesterol (non-HDL-C) was calculated by subtraction of HDL-C from TC [33]. Concentrations of plasma lipoproteins were classified according to recommendations of the European Atherosclerosis Society and European Guidelines on Cardiovascular Disease Prevention in Clinical Practice (TG $<1.7 \mathrm{mmol} / \mathrm{l}, \mathrm{TC}<4.5 \mathrm{mmol} / \mathrm{l}$, HLD-C $>1.0 \mathrm{mmol} / \mathrm{l}, \mathrm{LDL}-\mathrm{C}<2.5 \mathrm{mmol} / \mathrm{l}$, non-HDL $<$ $2.5 \mathrm{mmol} / \mathrm{l}[34,35]$. Plasma insulin was assayed using a standard radioimmunoassay with monoclonal antibodies against insulin and commercial kits (BioSource, Belgium). The sensitivity of the method was $1 \mu \mathrm{IU} / \mathrm{ml}$, intra and inter-assay coefficients of variation were $6.8 \%$ and $9.3 \%$, respectively. All analyses were run in duplicate.

\section{Statistical analyses}

Data are presented as mean $\pm \mathrm{SD}$. All variables were checked for normality using the Shapiro-Wilk test. The Pearson correlation coefficients were calculated for logarithmically (e-based) transformed data. Moreover, biochemical 
Table 1 Anthropometric characteristics and biochemical variables in young healthy men (means $\pm S D$ )

\begin{tabular}{|c|c|}
\hline Variable & $n=114$ \\
\hline Age (years) & $21.7 \pm 1.4$ \\
\hline Weight (kg) & $77.2 \pm 12.2$ \\
\hline Height (cm) & $180.3 \pm 6.7$ \\
\hline BMI & $23.7 \pm 3.3(25.4)^{*}$ \\
\hline Waist (cm) & $80.7 \pm 8.9(2.0)^{*}$ \\
\hline ABSI & $0.073 \pm 0.003$ \\
\hline Glucose (mmol/l) & $4.8 \pm 0.5(6.1)^{\wedge}$ \\
\hline Insulin ( $\mu \mid \mathrm{U} / \mathrm{ml})$ & $10.5 \pm 6.4$ \\
\hline TG (mmol/l) & $0.9 \pm 0.4(6.1)^{\wedge}$ \\
\hline TC (mmol/l) & $4.5 \pm 0.8(24.5)^{\wedge}$ \\
\hline $\mathrm{HDL}-\mathrm{C}(\mathrm{mmol} / \mathrm{l})$ & $1.4 \pm 0.3(8.8)^{\wedge}$ \\
\hline LDL-C (mmol/l) & $2.7 \pm 0.7(25.4)^{\wedge}$ \\
\hline Non-HDL (mmol/l) & $3.1 \pm 0.8(29.8)^{\wedge}$ \\
\hline
\end{tabular}

BMI - body mass index; ABSI- a body shape index; TG-triacylglycerols; TC-total cholesterol; HDL-C- HDL- cholesterol; LDL-C - LDL-cholesterol; percent of participants with overweight and obesity; ^ percent of participants with disturbed biochemical variables.

variables were interpreted with respect to lower and upper quartile of BMI and ABSI and the Mann-Whitney test was used for data comparison. A p value $\leq 0.05$ was considered to be statistically significant. All calculations were carried out using the Statistica v.7 (Statsoft, Illinois, USA).

\section{Results}

Baseline characteristics of the participants are presented in Table 1. According to BMI standards $74.6 \%$ of participants were normal weight, $18.4 \%$ were overweight, and $7.0 \%$ were obese. Only $2.0 \%$ of our subjects were characterized by higher than recommended waist circumference. Circulating glucose and triacylglycerols were higher than normal in similar percentages of students (6.1\%). Slightly more participants (8.8\%) were characterized by lower than normal HDL-cholesterol. On the contrary, higher than normal TC, LDL-C and non-HDL-C were observed in $24.5 \%, 25.4 \%$ and $29.8 \%$ of participants, respectively.

BMI was slightly, but significantly correlated only with circulating TG $(r=0.330, p<0.001)$. On the contrary, ABSI was slightly, but significantly correlated with plasma levels of insulin $(\mathrm{r}=0.360, \mathrm{p}<0.001)$, TC $(\mathrm{r}=0.270, \mathrm{p}<0.002)$, LDL$\mathrm{C}$ and non-HDL-C $(\mathrm{r}=0.300, \mathrm{p}<0.001)$ (data not shown).

In participants at the upper BMI quartile circulating TG was higher (by $50 \%, \mathrm{p}<0.05$ ) than in their counterparts at the lower BMI quartile (Table 2). Subjects representing the upper quartile of ABSI were characterized by higher plasma levels of insulin, TC, LDL-C and non-HDL (by $92 \%, 11 . \%, 29 \%$ and $21 \%$, respectively, $\mathrm{p}<0.001$ ) in comparison with subjects at the lower ABSI quartile.

\section{Discussion}

The most important finding of our study concerns ABSI, which is better correlated to changes in circulating TC and insulin than BMI in young sedentary men. It is worth noting that the homogeneity of our participants according to age and sex strengthens our findings. Additionally, taking into account that disturbances in biochemical parameters (insulin, glucose, and lipoproteins) bring about health deteriorations, it could be tentatively postulated that ABSI may be of importance in risk prognosis of type 2 diabetes and/or atherogenesis [36]. On the other hand, it should be stressed that ABSI validity in the prognosis of cardiovascular disease (CVD) is far from being elucidated since Maessen et al. [37] have not found ABSI capable of determining the presence of this disease in middle-aged subjects.

It should be stressed that in some way ABSI agrees with the WHO recommendation concerning waist circumference inclusion into health risk evaluation [30]. Similarly, other authors have suggested that both BMI and WC contribute to the prediction of body adiposity in white men and women [38]. The importance of WC measurements in diagnosis of health risk has been suggested by many authors since it has been postulated that WC provides indirect information about visceral fat accumulation $[39,40]$. At present it is well documented that visceral fat due to its location and metabolic characteristics contributes to distorted metabolism to a much greater extent than subcutaneous fat $[41,42]$.

However, it is worth noting that mathematical correlations between metabolic variables and surrogate indices of

Table 2 Biochemical variables in young healthy men according to lower and upper quartiles of BMI and ABSI

\begin{tabular}{|c|c|c|c|c|c|c|c|}
\hline Variable & Glucose & Insulin & TG & $\mathrm{TC}$ & HDL-C & LDL-C & Non-HDL \\
\hline \multicolumn{8}{|l|}{ BMI } \\
\hline Q1 $(20.0 \pm 0.9)$ & $4.8 \pm 0.6$ & $10.4 \pm 7.2$ & $0.8 \pm 0.4$ & $4.5 \pm 0.9$ & $1.4 \pm 0.3$ & $2.7 \pm 0.8$ & $3.0 \pm 08$ \\
\hline Q $4(28.2 \pm 2.8)$ & $5.1 \pm 0.4$ & $10.5 \pm 4.8$ & $1.2 \pm 0.5^{\mathrm{a}}$ & $4.5 \pm 0.8$ & $1.3 \pm 0.3$ & $2.7 \pm 0.8$ & $3.2 \pm 0.8$ \\
\hline \multicolumn{8}{|l|}{ ABSI } \\
\hline Q1 $(0.069 \pm 0.001)$ & $4.9 \pm 0.5$ & $7.2 \pm 2.9$ & $0.9 \pm 0.4$ & $4.3 \pm 0.8$ & $1.4 \pm 0.2$ & $2.4 \pm 0.8$ & $2.9 \pm 0.8$ \\
\hline Q $4(0.077 \pm 0.002)$ & $4.9 \pm 0.5$ & $13.8 \pm 7.6^{b}$ & $0.9 \pm 0.4$ & $4.8 \pm 0.9$ & $1.3 \pm 0.3$ & $3.1 \pm 0.8^{b}$ & $3.5 \pm 0.8^{b}$ \\
\hline
\end{tabular}

For abbreviations see Table $1 ; \mathrm{Q}_{1}^{\prime} \mathrm{Q}_{4}$ - lower and upper quartile, respectively; ${ }^{\mathrm{a}} \mathrm{P}<0.05 ;{ }^{\mathrm{b}} \mathrm{P}<0.001$. 
fatness found in our study do not mean a direct causeeffect relationship. On the other hand, marked differences in metabolic profiles of subjects selected according to lower and upper quartiles of ABSI may suggest that ABSI, but not BMI, depicts variability in circulating insulin and lipoproteins in participants of our study mostly characterized by normal body fat according to BMI standards. Thus, it seems feasible that ABSI allows diagnosis of slight metabolic disturbances observed in otherwise healthy subjects $[43,44]$. In addition, assuming that lower and upper quartiles of BMI varied by $41 \%$ (28.2 versus 20.0 ) and ABSI quartiles differ by $11.6 \%$ ( 0.077 versus 0.069$)$ it seems that even minor changes in ABSI provide information about variability in metabolic risk.

However, more studies are needed to prove this hypothesis, because of limitations of our study: the low number of participants from one social group, living in a big city, and representing one sex and one ethnicity.

\section{Conclusions}

Our study evaluated relationships between two surrogate measures of body composition - body mass index (BMI) and a body shape index (ABSI) with blood biochemical variables which contribute to health risk (glucose and lipoproteins).

Participants classified according to lower and upper quartile of ABSI markedly differ with respect to circulating insulin, total cholesterol, LDL-cholesterol and non-HDLcholesterol. On the contrary, participants classified according to lower and upper quartile of BMI slightly differ exclusively with respect to circulating triacylglycerols.

Thus, in young and otherwise healthy sedentary men ABSI is a better predictor than BMI of variability in biochemical parameters, which may indicate disturbed metabolic processes.

\section{Competing interests}

The authors declare that they have no competing interests.

\section{Authors' contributions}

MM conceived the study, carried out biochemical measurements and drafted the manuscript. GL participated in the design of the study and performed data analysis. AK carried out anthropometric measurements and participated in the design of the study. JT participated in study coordination and helped to draft the manuscript. All authors read and approved the manuscript.

\section{Acknowledgements}

We would like to thank all the students who volunteered for the study.

Received: 18 September 2014 Accepted: 2 February 2015

Published online: 27 February 2015

\section{References}

1. Camici M, Galetta F, Capri A: Obesity and increased risk for atherosclerosis and cancer. Int Med 2014, http://dx.doi.org/10.4172/2165-8048.1000154

2. Sun $G$, French $C R$, Martin GR, Younghusband B, Green RC, Xie Y, et al. Comparison of multifrequency bioelectrical impedance analysis with dual-Xray absorptiometry for assessment of percentage body fat in a large, healthy population. Am J Clin Nutr. 2005;81:74-8.
3. Camhi SM, Bray GA, Bouchard C, Greenway FI, Johnson WD, Newton RL, et al. The relationship of waist circumference and BMI to visceral, subcutaneous, and total body fat: sex and race differences. Obesity. 2011;19:402-8

4. Neamat-Allah J, Wald D, Hüsing A, Teucher B, Wendt A, Delorme S, et al. Validation of anthropometric indices of adiposity against whole-body magnetic resonance imaging - a study within the German European Prospective Investigation into Cancer and Nutrition (EPIC) Cohorts. PLoS ONE. 2014;9:e91586.

5. Anthropometry procedure manual. www.cdc.gov/nchs/data/nhanes/ nhanes_07_08/mnual_an.pfd

6. Feller S, Boeing H, Pischon T. Body mass index, waist circumference, and the risk of type 2 diabetes mellitus. Dtsch Arztebl Int. 2010;107:470-6.

7. Flint AJ, Rexrode KM, Hu FB, Glynn RJ, Caspard H, Manson JE, et al. Body mass index, waist circumference, and risk of coronary heart disease: a prospective study among men and women. Obes Res Clin Pract. 2010;4:e171-81.

8. Feng R-N, Zhao C, Wang C, Niu Y-C, Li K, Guo F-C, et al. BMl is strongly associated with hypertension and waist circumference is strongly associated with type 2 diabetes and dyslipidemia, in northern Chinese adults. J Epidemiol. 2012;22:317-23.

9. Heo M, Faith MS, Pietrobelli A, Heymsfield SB. Percentage of body fat cutoffs by sex, age, and race-ethnicity in the US adult population from NHAHES 1999-2004. Am J Clin Nutr. 2012;95:594-602.

10. Shah NR, Braverman ER. Measuring adiposity in patients: the utility of body mass index (BMI), percent body fat, and leptin. PLOS ONE. 2012;7:e33308. doi:101371/journal.pone.0033308.

11. Youn C-H, Bezerra HG, Wu T-H, Yang F-S, Liu C-C, Wu Y-J, et al. The normal limits, subclinical significance, related metabolic derangements and distinct biological effects of body site-specific adiposity in relatively healthy population. PLOS ONE. 2013;8:e61997. doi:101371/journal.pone.0061997.

12. De Larochelliěre E, Côté J, Gillbert G, Bibeau K, Ross MK, Dion-Roy V, et al. Visceral/epicardial adiposity in non-obese and apparently healthy young adults: association with the cardiometabolic profile. Athrosclerosis. 2014:234:23-9

13. Nazare J-A, Smith JD, Borel A-L, Haffner SM, Baělkau B, Ross R, et al. Ethnic influences on the relations between abdominal subcutaneous and visceral adiposity, liver ft, and cardiometabolic risk profile: the international study of prediction of intra- abdominal adiposity and its relationship with cardiometabolic risk/intra-abdominal adiposity. Am J Clin Nutr. 2012;96:714-26.

14. Odegaard AO, Pereira MA, Koh W-P, Gross MD, Duval S, Yu MC, et al. BMl, all-cause and cause-specific mortality in Chinese Singaporean men and women: the Singapore Chinese health study. PLOS ONE. 2010;5:e14000. doi:101371/journl.pone.0014000.

15. Kokinos P, Myers J, Faselis C, Doumas M, Kheirbek R, Nylen E. BMI-mortality paradox and fitness in African American and Caucasian men with type 2 diabetes. Diabetes Care. 2012;35:1021-7.

16. Chen Y, Copeland WK, Vendanthn R, Grant E, Lee JE, Gu D, et al. Association between body mass index and cardiovascular disease mortality in east Asians and south Asians: pooled analysis of prospective data from the Asia Cohort Consortium. BMJ. 2013;347:f5446. doi:10.1136/bmj.f5446.

17. Zaccagni L, Barbieri D, Gualdi-Russo E. Body composition and physical activity in Italian university students. J Transl Med. 2014;12:120. http://www.translationalmedicine.com/content/12/1/120

18. Heymsfield SB, Scherzer R, Piertobelli A, Lewis CE, Grunfeld C. Body mass index as a phenotyping expression of adiposity: quantitative contribution of muscularity in a population based sample. Int J Obes. 2009;33:1363-73.

19. Ashwell M, Gunn P, Gibson S. Waist-to-height ratio is a better screening tool than waist circumference and BMI for adult cardiometabolic risk factors: systemic review and meta-analysis. Obes Rev. 2012;13:275-86.

20. Taylor RW, Jones IE, Williams SM, Goulding A. Evaluation of waist circumference, waist-to-hip ratio and the conicity index as a screening tools for high trunk fat mass, as measured by dual-energy $\mathrm{X}$-ray absorptiometry, in children aged 3-19 y. Am J Clin Nutr. 2000;72:490-5.

21. Heymsfield SB, Heo M, Pietrobelli A. Are adult body circumferences associated with height? Relevance to normative ranges and circumferential indexes. Am J Clin Nutr. 2011:93:302-7.

22. Lichtash CT, Ciu J, Guo X, Chen Y-DI, Hsueh WA, Rotter Jl, et al. Body adiposity index versus body mass index and other anthropometric treats $\mathrm{s}$ correlates of cardiometabolic risk factors. PLOS ONE. 2013;8:e65954. doi:10.137/journal. pone.0065954.

23. Krakauer NY, Krakauer JC. A new body shape index predicts mortality hazards independently of body mass index. PLOS ONE. 2012;7:e39504. doi:10.1371/journal.pone 0039504. 
24. Duncan MJ, Mota J, Vale S, Santos MP, Ribeiro JC. Associations between body mass index, waist circumference and body shape index with resting blood pressure in Portuguese adolescents. Am J Hum Biol. 2013;40:163-7.

25. He S, Chen X. Could the new body shape index predict the new onset of diabetes mellitus in the Chinese population? PLOS ONE. 2013;8:e50573. doi:10.1371/journal.pone. 0050573.

26. Cheung YB. "A body shape index" in middle-age and older Indonesian population: scaling exponents and association with incident hypertension. PLOS ONE. 2014;9:e85421. doi:10.1371/journal.pone.00 85421.

27. Haghighatdoost F, Sarrafzadegan N, Mofammadifard N, Asgary S, Botsham $M$, Azadbakht L. Assessing body shape index as a risk predictor for cardiovascular disease and metabolic syndrome among Iranian adults. Nutrition. 2014:30:636-44.

28. WHO Expert Consultation. Appropriate body-mass index for Asian populations and its implications for policy and intervention strategies. Lancet. 2004;363:157-163.

29. Després J-P. Body fat distribution and risk of cardiovascular disease. Circulation. 2012;126:1301-13.

30. World Health Organization (WHO). Waist circumference and waist-to-hip ratio: Report of a WHO Expert Consultation. Geneva: WHO; 2008.

31. International Diabetes Federation. Global Guideline for type 2 diabetes. www.idf.org/sites/default/files/IDF\%20T2DM\%20Guideline.pdf

32. Friedewald WT, Levy R, Fredricson D. Estimation of concentrations of low density lipoprotein concentrations without use of the preparative ultra-centrifugation. Clin Chem. 1972;18:499-504.

33. Orakzai SH, Nasir K, Blaha M, Blumenthal RS, Raggi P. Non-HDL cholesterol is strongly associated with coronary artery calcification in asymptomatic individuals. Atherosclerosis. 2009:202:289-95.

34. European Atherosclerosis Society Consensus Panel. Triglyceride-rich lipoproteins and high-density lipoprotein cholesterol in patients at high risk of cardiovascular disease: evidence and guidance for management. Eur Heart J. 2011;32:1345-61.

35. Perk J. European Guidelines on cardiovascular disease prevention in clinica practice. Eur Heart J. 2012;33:1635-701.

36. Raeven GM. Insulin resistance: the link between adiposity and cardiovascular disease. Med Clin North Am. 2011:95:875-92.

37. Maessen MFH, Eijsfogels TMH, Verhaggen RJHM, Hopmn MTE, Verbeek ALM, de Vegt F. Entering a new era of body indices: the feasibility of a body shape index and body roundness index to identify cardiovascular health status. PLoS One. 2014:9:e107212.

38. Janssen I, Heymsfield SB, Allison DB, Kotler DP, Ross R. Body mass index and waist circumference independently contribute to the prediction of nonabdominal, abdominal subcutaneous, and visceral fat. Am J Clin Nutr. 2002;75:683-8

39. Pouliot M-C, Desprěs J-P, Lemieux S, Moorjani S, Bouchard C, Tremblay A, et al. Waist circumference and abdominal sigittal diameter: best simple anthropometric indexes of abdominal visceral adipose tissue accumulation and related cardiovascular risk in men and women. Am J Cardiol. 1994;73:460-3.

40. Lofgren I, Herron K, Zern T, West K, Patalay M, Shachter NS, et al. Waist circumference is a better predictor than body mass index of coronary hart disease risk in overweight premenopausal women. J Nutr. 2004;134:1071-6.

41. Coral-Romero A, Sert-Kuniyoshi FH, Sierra-Johnston J, Orban M, Gami AQ, Davison D, et al. Modest visceral fat gain cause endothelial dysfunction in healthy humans. J Am Coll Cardiol. 2010;56:662-4.

42. Liu J, Fox CS, Hickson DA, May WD, Hirstone KG, Carr JJ, et al. Impact of abdominal visceral and subcutaneous adipose tissue on cardiometabolic risk factors: the Jackson Heart Study. J Clin Endocrinol Metab. 2010;95:5419-26.

43. Wildman RP, Muntner P, Reynolds K, McGinn AP, Rajpathak S, Rosetti Wylie J, et al. The obese without cardiometabolic risk factor clustering and the normal weight with cardiometabolic risk factor clustering. Arch Intern Med. 2008;168:1617-24

44. Sucurro E, Marini MA, Frontoni S, Hibal ML, Andreozzi F, Lauro R, et al. Insulin secretion in metabolically obese, but normal weight, and in metabolically healthy but obese individuals. Obesity. 2008;16:1881-6.

\section{Submit your next manuscript to BioMed Central and take full advantage of:}

- Convenient online submission

- Thorough peer review

- No space constraints or color figure charges

- Immediate publication on acceptance

- Inclusion in PubMed, CAS, Scopus and Google Scholar

- Research which is freely available for redistribution

Submit your manuscript at www.biomedcentral.com/submit 